\title{
Supporting Information for: From Neutral Aniline to Aniline Trication: A Computational and Experimental Study
}

G. L. Gutsev, ${ }^{* a}$ H. A. López Peña, ${ }^{b}$ S. L. McPherson, ${ }^{b}$ D. Ampadu Boateng, ${ }^{b}$ B. R. Ramachandran, ${ }^{c}$ L. G. Gutsev, ${ }^{\mathrm{c}, \mathrm{d}}$ K. M. Tibbetts*b

a Department of Physics, Florida A\&M University, Tallahassee, Florida 32307, United States

b Department of Chemistry, Virginia Commonwealth University, Richmond, Virginia 23284, United States

' Institute for Micromanufacturing, Louisiana Tech University, Ruston, LA 71272, United States

d Institute of Problems of Chemical Physics of Russian Academy of Sciences, Chernogolovka, Moscow District 142432, Russia

TABLE S1. Energies (in eV) of Singlet-Triplet Splitting for the Isomers of $\mathrm{C}_{6} \mathbf{H}_{5} \mathrm{NH}_{2}$ and $\mathrm{C}_{6} \mathrm{H}_{5} \mathrm{NH}_{2}{ }^{+2}$ along with the Energies of Doublet-Quartet Splitting for the Isomers of $\mathrm{C}_{6} \mathrm{H}_{5} \mathrm{NH}_{2}{ }^{+}$and $\mathrm{C}_{6} \mathrm{H}_{5} \mathrm{NH}_{2}{ }^{+3}$ Shown in Fig. 1 of the Text in the Order Shown in the figure. All Values (in eV) Are Computed at the BPW91/6-311+G* Level using Eq. 1 of the Text:

$$
\Delta(\mathrm{A}-\mathrm{B})=E_{\text {tot }}^{\mathrm{el}}(\mathrm{A})+E_{0}(\mathrm{~A})-\left[E_{\text {tot }}^{\mathrm{el}}(\mathrm{B})+E_{0}(\mathrm{~B})\right]
$$

where $A=S$ or $D$ and $B=T$ or $Q$.

\begin{tabular}{|c|c|c|c|c|c|c|}
\hline & & $\begin{array}{l}\text { Ground } \\
\text { state }\end{array}$ & Isomer 1 & Isomer 2 & Isomer 3 & Isomer 4 \\
\hline $\mathrm{C}_{6} \mathrm{H}_{5} \mathrm{NH}_{2}$ & $\Delta(\mathrm{S}-\mathrm{T})$ & 3.23 & 2.21 & 1.62 & 2.19 & 0.51 \\
\hline $\mathrm{C}_{6} \mathrm{H}_{5} \mathrm{NH}_{2}{ }^{+}$ & $\Delta(\mathrm{D}-\mathrm{Q})$ & 3.47 & 3.62 & 3.76 & 3.48 & 2.98 \\
\hline $\mathrm{C}_{6} \mathrm{H}_{5} \mathrm{NH}_{2}{ }^{+2}$ & $\Delta(\mathrm{S}-\mathrm{T})$ & 2.17 & 2.58 & 2.05 & 1.60 & 0.61 \\
\hline $\mathrm{C}_{6} \mathrm{H}_{5} \mathrm{NH}_{2}{ }^{+3}$ & $\Delta(\mathrm{D}-\mathrm{Q})$ & 3.32 & 2.49 & 1.42 & 1.75 & 1.95 \\
\hline
\end{tabular}

TABLE S2. Total Energies (in Hartree), Zero Point Vibrational Energies, and Squared Spin Values Computed for Aniline with the charge $q=0 .+1,+2$, and +3 Using Five Methods from Three Groups (DFT, Hybrid DFT, post-HF). BPW91/6-311++G(3df)

\begin{tabular}{|c|c|c|c|c|c|c|c|}
\hline $\begin{array}{c}\text { Charge } \\
q\end{array}$ & $2 S+1$ & $\begin{array}{l}\text { BPW91 Total } \\
\text { Energy: } \\
\text { Aniline }^{9}\end{array}$ & $\overline{Z P E}$ & $\langle$ S2 $\rangle$ & $2 S+1$ & $\begin{array}{l}\text { TE An } \text { An+1 at }^{\text {at }} \\
\text { An }{ }^{q} \text { geometry } \\
\text { (vertical } \\
\text { detachment) }\end{array}$ & $\langle$ S2 $>$ \\
\hline 0 & 1 & -287.65325 & 3.087 & 0.000 & 2 & -287.36829 & 0.757 \\
\hline \multirow[t]{2}{*}{+1} & 2 & -287.37928 & 3.104 & 0.758 & 1 & -286.87354 & 0.000 \\
\hline & & & & & 3 & -286.84832 & 2.007 \\
\hline+2 & 1 & -286.90394 & 3.130 & 0.000 & 2 & -286.13078 & 0.756 \\
\hline \multirow[t]{2}{*}{+3} & 2 & -286.14362 & 3.007 & 0.766 & $\overline{1}$ & -285.14376 & 0.000 \\
\hline & & & & & 3 & -285.10954 & 2.004 \\
\hline
\end{tabular}




\begin{tabular}{|c|c|l|l|l|c|c|c|}
\hline $\mathrm{q}$ & $2 \mathrm{~S}+1$ & $\mathrm{~B} 3 \mathrm{LYP}$ & $\mathrm{ZPE}$ & $<\mathrm{S} 2\rangle$ & $2 \mathrm{~S}+$ & $\mathrm{TE}$ & $<\mathrm{S} 2\rangle$ \\
\hline 0 & 1 & -287.69710 & 3.169 & 0.000 & 2 & -287.40825 & 0.766 \\
\hline+1 & 2 & -287.42054 & 3.186 & 0.769 & 1 & -286.91051 & 0.000 \\
\hline & & & & & 3 & -286.88591 & 2.013 \\
\hline+2 & 1 & -286.94524 & 3.213 & 0.000 & 2 & -286.17100 & 0.757 \\
\hline+3 & 2 & -286.18587 & 3.092 & 0.774 & 1 & -285.18599 & 0.000 \\
\hline & & & & & 3 & -285.14734 & 2.004 \\
\hline
\end{tabular}

CAM-B3LYP/6-311++G(3df)

\begin{tabular}{|c|c|c|l|l|c|c|c|}
\hline $\mathrm{q}$ & $2 \mathrm{~S}+1$ & CAM-B3LYP & ZPE & $<\mathrm{S} 2>$ & $2 \mathrm{~S}+1$ & $\mathrm{TE}$ & $<\mathrm{S} 2\rangle$ \\
\hline 0 & 1 & -287.53176 & 3.200 & 0.000 & 2 & -287.24008 & 0.781 \\
\hline+1 & 2 & -287.25376 & 3.220 & 0.786 & 1 & -286.73979 & 0.000 \\
\hline & & & & & 3 & -286.71509 & 2.020 \\
\hline+2 & 1 & -286.77671 & 3.246 & 0.000 & 2 & -286.00158 & 0.760 \\
\hline+3 & 2 & -286.01751 & 3.121 & 0.787 & 1 & -285.01562 & 0.000 \\
\hline & & & & & 3 & -284.97615 & 2.006 \\
\hline
\end{tabular}

MP2/6-311++G(3df)

\begin{tabular}{|c|c|l|l|l|l|c|c|l|l|}
\hline $\mathrm{q}$ & $2 \mathrm{~S}+1$ & $\mathrm{MP2}$ & $\mathrm{PMP2}$ & $\mathrm{ZPE}$ & $<\mathrm{S} 2>$ & $2 \mathrm{~S}+1$ & $\mathrm{MP2}$ & $\mathrm{PMP2}$ & $<\mathrm{S} 2\rangle$ \\
\hline 0 & 1 & -286.94804 & & 3.160 & 0.000 & 2 & -286.62548 & -286.64860 & 1.130 \\
\hline+1 & 2 & -286.64067 & -286.66185 & 3.247 & 1.074 & 1 & -286.11326 & -286.18376 & 0.867 \\
\hline & & & & & & 3 & -286.10538 & -286.11432 & 2.123 \\
\hline+2 & 1 & -286.19284 & & 3.234 & 0.000 & 2 & -285.40972 & -285.41292 & 0.787 \\
\hline+3 & 2 & -285.42048 & -285.43136 & 3.145 & 0.927 & 1 & -284.43126 & -284.43126 & 0.000 \\
\hline & & & & & & 3 & -284.37541 & -284.38015 & 2.076 \\
\hline
\end{tabular}

$\operatorname{CCSD}(\mathrm{T}) / 6-311++\mathrm{G}(3 \mathrm{df}) / / \mathrm{BPW} 91 / 6-311++\mathrm{G}(3 \mathrm{df})$

\begin{tabular}{|c|c|c|l|l|c|c|l|l|}
\hline $\mathrm{q}$ & $2 \mathrm{~S}+1$ & $\mathrm{CCSD}(\mathrm{T})$ & LAmp & $\langle\mathrm{S} 2\rangle$ & $2 \mathrm{~S}+1$ & VDE & $<\mathrm{S} 2\rangle$ & LAmp \\
\hline 0 & 1 & -287.03588 & $5.40 \mathrm{D}-02$ & 0.000 & 2 & -286.74387 & 1.158 & $1.48 \mathrm{D}-01$ \\
\hline+1 & 2 & -286.75622 & $1.45 \mathrm{D}-01$ & 1.167 & 1 & -286.25241 & 1.031 & $3.02 \mathrm{D}-01$ \\
\hline & & & & & 3 & -286.22407 & 2.134 & $1.24 \mathrm{D}-01$ \\
\hline+2 & 1 & -286.28910 & $5.89 \mathrm{D}-02$ & 0.000 & 2 & -285.51817 & 0.789 & $7.38 \mathrm{D}-02$ \\
\hline+3 & 2 & -285.53146 & $1.24 \mathrm{D}-01$ & 0.973 & 1 & -284.54319 & 0.000 & $5.58 \mathrm{D}-02$ \\
\hline & & & & & 3 & -284.50089 & 2.106 & $1.74 \mathrm{D}-01$ \\
\hline
\end{tabular}

\section{Additional NBO discussion}

There is a further shortening of the $\mathrm{C}-\mathrm{N}$ bond in the dication singlet state, which is reasonable since the antibonding $\sigma_{C N}^{*}$ orbital loses $0.0038 e$ (Table S3). The only lone pair that remains in the dication belongs to the para-carbon, whereas neither nitrogen nor its carbon neighbor have lone pairs. Compared to the cation case, there are a total of four electrons occupying two bonding $\mathrm{C}-\mathrm{N}$ MOs in the dication, which corresponds to a double 
bond. The total disappearance of lone pair density on the nitrogen in both representations removes the LPN $\rightarrow$ $\mathrm{LP}_{\mathrm{C} 1}$ interaction, consequently $\pi c 2 \mathrm{C3}$ also loses some density (Table S4)

When we compare the lone pairs of the trication to the dication we note (Table S4) that there appears to be a significant amount of lone pair density in the $\beta$ representation and almost no lone pair density in the $\alpha$, as in the dication. Both $\mathrm{C} 2-\mathrm{C} 3$ bonds decrease by half a bond order to 1.5; as a result, the $\mathrm{C} 2-\mathrm{C} 3$ bond stretches by $0.045 \AA$. In the $\alpha$-spin representation there are still two bonding NBOs in the $\alpha$-spin representation of the $\mathrm{C}\left(s p^{2}\right)$ $\mathrm{N}\left(s p^{1.5}\right)$ and two bonding NBOs of the same type in the $\beta$-spin representation, thus the bond order is still two. This is also the first structure in the series of anilines that is not flat, the loss of aromaticity (which we will confirm below) allows $\mathrm{C} 4$ to move out of the plane of the aromatic ring. If we consider the $\mathrm{z}$ axis to be perpendicular to the plane of the aromatic ring, then C4 lies $0.272 \AA$ above it while the Nitrogen is $0.299 \AA$ below it (Fig. 11 in the main text).

TABLE S3. Bond Order of the Aniline N-C Bond and Electron Occupation of the $\sigma_{N C}, \pi_{N C}, \sigma_{N C}^{*}, \pi_{N C}^{*}$ and the $F(i, j)$ Elements Corresponding to the $L P_{N} \rightarrow L P_{C 1}$ Electron Transfer.

\begin{tabular}{|c|c|c|c|c|c|c|c|}
\hline Species & $\begin{array}{l}\text { Spin } \\
\text { representation }\end{array}$ & $\begin{array}{l}\text { Bond } \\
\text { Order } \\
(\mathrm{N}-\mathrm{C}) \\
\end{array}$ & $\sigma_{N C}$ & $\pi_{N C}$ & $\sigma_{N C}^{*}$ & $\pi_{N C}^{*}$ & $\begin{array}{l}\mathbf{L P}_{\mathrm{N}} \rightarrow \\
\mathbf{L P}_{\mathrm{C} 1} \\
(\mathrm{kcal} / \mathrm{mol})\end{array}$ \\
\hline \multirow[t]{2}{*}{ Neutral } & $\alpha$ & \multirow[t]{2}{*}{1} & $(s p 2.5) 0.9961$ & - & $(s p 2.5) 0.0105$ & - & 22.39 \\
\hline & $\beta$ & & $(s p 2.5) 0.9961$ & - & $(s p 2.5) 0.0105$ & - & 22.39 \\
\hline \multirow[t]{2}{*}{ Cation } & $\alpha$ & \multirow[t]{2}{*}{1.5} & $(s p 2.5) 0.9947$ & - & $(s p 2.5) 0.0094$ & - & 37.61 \\
\hline & $\beta$ & & $(s p 2.5) 0.9968$ & $(p) 0.9191$ & $(s p 2.5) 0.0092$ & $(p) 0.0597$ & 1.34 \\
\hline \multirow[t]{2}{*}{ Dication } & $\alpha$ & \multirow[t]{2}{*}{2} & $(s p 2.3) 0.9455$ & $(p) 0.9455$ & $(s p 2.3) 0.0074$ & $(p) 0.0661$ & - \\
\hline & $\beta$ & & $(s p 2.3) 0.9975$ & $(p) 0.9455$ & $(s p 2.3) 0.0074$ & $(p) 0.0661$ & 1.63 \\
\hline \multirow[t]{2}{*}{ Tricatio } & $\alpha$ & \multirow[t]{2}{*}{2} & $(s p 2) 0.99781$ & $(p) 0.9240$ & $(s p 2) 0.00766$ & $(p) 0.0576$ & 1.63 \\
\hline & $\beta$ & & $(s p 2) 0.99783$ & $(p) 0.9322$ & $(s p 2) 0.00783$ & $(p) 0.0518$ & 1.63 \\
\hline
\end{tabular}


TABLE S4. Bond order of the Aniline C2-C3 Bond and Electron Occupation of the Aniline Lone Pairs L $P_{N}, L P_{C 1}, L P_{C 2}, L P_{C 3}, L P_{C 4}$ as well as the Occupation of the two $\pi_{C 2 C 3}$ orbitals.

\begin{tabular}{|c|c|c|c|c|c|c|c|c|}
\hline Species & $\begin{array}{l}\text { Spin } \\
\text { representatio } \\
\text { n }\end{array}$ & $\begin{array}{l}\text { Bond } \\
\text { Order } \\
\text { (C2-C3) }\end{array}$ & $\mathbf{L} \mathbf{P}_{\mathbf{N}}$ & $\mathbf{L P}_{\mathbf{C 1}}$ & $\mathbf{L P}_{\mathbf{C} 2}$ & $\mathbf{L P}_{\mathbf{C} 3}$ & $\mathbf{L P}_{\mathbf{C 4}}$ & $\pi_{C 2 C 3}$ \\
\hline \multirow[t]{2}{*}{ Neutral } & $\alpha$ & 2 & - & 0.52419 & - & - & 0.49193 & 0.85616 \\
\hline & $\beta$ & & - & 0.52419 & - & - & 0.49193 & 0.85616 \\
\hline \multirow[t]{2}{*}{ Cation } & $\alpha$ & 2 & 0.906 & 0.50204 & - & - & 0.57362 & 0.84968 \\
\hline & $\beta$ & & - & - & - & - & 0.2565 & 0.84706 \\
\hline \multirow{2}{*}{ Dication } & $\alpha$ & 2 & - & - & - & - & 0.28048 & 0.82856 \\
\hline & $\beta$ & & - & - & - & - & 0.28048 & 0.82856 \\
\hline \multirow{2}{*}{ Trication } & $\alpha$ & 1.5 & - & - & - & - & 0.23208 & 0.8606 \\
\hline & $\beta$ & & - & - & 0.15384 & 0.23394 & 0.31831 & - \\
\hline
\end{tabular}

In the case of the 3MP structure, we will number atoms by taking the methylene-bound carbon to be in the first position and then number clockwise (Fig. 10 in the main text) towards the nitrogen atom, which occupies the third position. According to the NBO analysis (Fig. 12 in the main text), the neutral 3MP has double bonds formed between nitrogen and $\mathrm{C} 4, \mathrm{C} 5$ and $\mathrm{C} 6$, and between the methylene carbon and $\mathrm{C} 1$. A lone pair is present on $\mathrm{C} 2$ but it is only half filled; the negative charge is spread among the nitrogen and carbon atoms of the ring except for $\mathrm{C} 2$, which serves as a bridge between the nitrogen and methylene group. This carbon donates a significant amount of its electron density to the neighbors. By analyzing the donor-acceptor interactions, we note a very strong $L P_{C 2} \rightarrow \pi_{N C 4}^{*}$ interaction $(51.6 \mathrm{kcal} / \mathrm{mol})$ that gives the $\pi_{N C 4}^{*}$ orbital a significant population of 0.75 $e$. There is also a weaker $L P_{C 2} \rightarrow \pi_{C 1 C m}^{*}$ interaction where $\mathrm{C}_{m}$ is the methylene carbon. The $\pi_{C 1 C m}^{*}$ orbital also holds a significant population of electrons: $0.35 e$ in total. Thus, it is clear that the instability of the neutral $3 \mathrm{MP}$ is due to the large amount of electron density donated to anti-bonding orbitals. If one considers similar antibonding orbitals in the case of the 3MP cation, then one can notice that they become noticeably different (see Table S4): the double bonds are formed between $\mathrm{C} 1$ and $\mathrm{C} 6$ as well as $\mathrm{C} 4$ and $\mathrm{C} 5$ but there is no double bond present between methylene and $\mathrm{C} 1$. The bond order of $\mathrm{CmC1}$ changes to 1.5 , which also removes half of the rather strong antibonding interaction in the neutral species. The natural charge comparison of the neutral and cationic state suggests that, surprisingly, it is not the nitrogen which gives up an electron but instead it is mostly the methylene 
and the inter-ring carbons. All of the charged states have lone pair density on the nitrogen, but not significant spin density (Table S5).

TABLE S5. Lone Pair Density of the Nitrogen in (3MP)

\begin{tabular}{|c|c|c|c|c|c|}
\hline $\begin{array}{l}\text { N lone } \\
\text { pair } \\
\end{array}$ & Rep & $\pi_{N C 4}^{*}$ & $\pi_{C 1 C m}^{*}$ & $\pi_{C 5 C 6}^{*}$ & $\mathbf{L} \mathbf{P}_{\mathbf{N}}$ \\
\hline \multirow[t]{2}{*}{ Neutral } & Alpha & 0.37599 & $\mathbf{0 . 1 7 5 7 7}$ & 0.11884 & - \\
\hline & Beta & 0.37599 & 0.17577 & 0.11884 & - \\
\hline \multirow[t]{2}{*}{ Cation } & Alpha & 0.32419 & 0.2531 & 0.12002 & - \\
\hline & Beta & 0.37599 & 0.12002 & 0.2531 & $0.73845+0.72361(p)$ \\
\hline \multirow[t]{2}{*}{ Dication } & Alpha & 0.01146 & 0.00978 & 0.06786 & $0.74147+0.702(p)$ \\
\hline & Beta & 0.01146 & 0.00978 & 0.06786 & $0.74147+0.702(p)$ \\
\hline \multirow[t]{2}{*}{ Trication } & Alpha & 0.19939 & - & 0.10141 & $0.76232(p)$ \\
\hline & Beta & 0.0001 & - & 0.00023 & $0.76271(p)$ \\
\hline
\end{tabular}

In the case of the $3 \mathrm{MP}$ dication, the $\pi_{N C 4}^{*}$ and $\pi_{C 1 C m}^{*}$ are nearly empty despite the fact that the bond order of both of these bonds remains 2. There is only one double bond within the ring between C6 and C5. There are two lone pairs present on the nitrogen with occupancies of 1.48 and 1.40 , one on $\mathrm{C} 2$ with occupancy of 0.72 , one on C4 with occupancy of 0.75 and one on the nitrogen's hydrogen with occupancy of 0.52 . The large number of lone pairs with significant occupancies is due to donor-acceptor interactions of the nitrogen lone pair with the carbon and hydrogen acceptors. The $\pi_{C 1 C m}$ orbital also donates some electron density to the C2 lone pair and $\pi_{C 5 C 6}$ donates some of its electron density to the $\mathrm{C} 4$ lone pair. The resulting charge distribution is very different from that of the neutral species: negative charges are on the first carbon, nitrogen and carbon five, which creates an alternating pattern of positive and negative centers (Fig. 10 in the main text). The negative centers do donate significant amounts of their electron density to the positive centers, which correspond to the donor-acceptor interactions. In the case of the trication we note only significant antibonding density of $\pi_{N C 4}^{*}$ and $\pi_{C 5 C 6}^{*}$ (Table S5), in this case the bond order of the bond $C_{1}-C_{m}$ is 1 and thus there the antibonding orbital $\pi_{C 1 C m}^{*}$ is not present.

These bonding patterns can be associated with the nuclear-independent chemical shift (NICS) values at the center of the ring, which are labeled as $\operatorname{NICS}(0)$. Our computed NICS $(0)$ value for neutral benzene is -7.79 in agreement with recent benchmarks. ${ }^{i}$ The neutral aniline $\operatorname{NICS}(0)$ is -7.44 , which means that it is also aromatic. Upon removing a single electron from aniline, the $\mathrm{NICS}(0)$ value increases substantially to 2.23 while the dication 
value is 16.86 meaning that they become anti-aromatic. This behavior can be related with the $\mathrm{C}-\mathrm{N}$ bond strengthening, which decreases the electron density within the ring system, thus destabilizing it. Meanwhile, the 3MP dication with a NICS $(0)$ value of -2.9 becomes weakly aromatic, which helps to explain its superior stability to the aniline dication with the neutral-type geometry. The neutral species of $3 \mathrm{MP}$ is anti-aromatic with the NICS $(0)$ value of 10.3 while the cation is somewhat aromatic with a NICS(0) value of -2.59 . In the case of the aniline trication, the state with the neutral aniline topology is strongly anti-aromatic with a NICS $(0)$ value of 9.64 whereas 4MP is weakly anti-aromatic with a $\operatorname{NICS}(0)$ value of 3.80 . That is, the aromaticity can be related with the preferred geometrical structure at each charged state of aniline.

\section{TABLE S6. Calculation of kinetic energy release of Coulomb explosion}

The equation used to calculate the kinetic energy of the fragments ejected during Coulomb explosion, adapted from Ref. 36, is

$$
E_{k}=\frac{(z e F)^{2}}{2 m}\left(\frac{t_{2}-t_{1}}{2}\right)^{2}
$$

where $z, e, F, m, t_{2}$, and $t_{1}$ are the charge number of the ion, elemental charge (in C), electric field for extraction (in $\mathrm{V} \mathrm{m}^{-1}$ or $\mathrm{N} \mathrm{C}^{-1}$ ), mass of the fragment (in $\mathrm{kg}$ ), time of flight of the fragment ejected away and towards the detector during precursor breakup respectively.

Kinetic energy of the fragments ejected during Coulomb explosion.

\begin{tabular}{|c|c|c|c|c|}
\hline Fragment & Peak label & $t_{1}(\mu \mathrm{s})$ & $t_{2}(\mu \mathrm{s})$ & $E_{k}(\mathrm{eV})$ \\
\hline $\mathrm{N}^{+}(m / z 14)$ & $\mathrm{A}$ & 4.572 & 4.694 & 9.6968 \\
\hline \multirow{2}{*}{$\mathrm{NH}^{+}(m / z 15)$} & $\mathrm{B}$ & 4.736 & 4.856 & 8.7560 \\
\cline { 2 - 5 } & $\mathrm{C}$ & 4.762 & 4.832 & 2.9795 \\
\hline \multirow{2}{*}{$\mathrm{NH}_{2}^{+}(m / z 16)$} & $\mathrm{D}$ & 4.882 & 5.02 & 10.8561 \\
\cline { 2 - 5 } & $\mathrm{E}$ & 4.902 & 4.994 & 4.8249 \\
\hline
\end{tabular}




\section{TABLE S7. Calculation of multichannel plate ion detection efficiency}

The ion detection efficiency $(\eta)$ at the MCP detector was calculated using the equation

$$
\log \eta=-0.257+0.161 x-0.239 x^{2}-0.0184 x^{3}-0.300 x^{4}
$$

with $x=\log \left(E / M^{0.5}\right)$, following the formula given in Ref. 68. $E$ is the kinetic energy (in $\mathrm{keV}$ ) and $M$ is the mass of the ion (in amu), $E$ can be calculated from the applied voltage in the TOF instrument. The obtained efficiencies were $0.4450,0.5394$, and 0.5729 for the aniline cation, dication, and trication respectively for a voltage of 4175 V.

Corrected and uncorrected yields of aniline cation, dication, and trication at the MCP detector considering the differences in detection efficiency.

\begin{tabular}{|c|c|c|c|}
\hline Ion & $\begin{array}{c}\text { Uncorrected } \\
\text { Yield \% }\end{array}$ & $\eta_{\text {rel }}{ }^{+}$ & $\begin{array}{c}\text { Corrected } \\
\text { Yield \% }\end{array}$ \\
\hline $\mathrm{An}^{+}$ & 100.0 & 1.00 & 100.0 \\
\hline $\mathrm{An}^{2+}$ & 83.5 & 1.21 & 68.9 \\
\hline $\mathrm{An}^{3+}$ & 12.0 & 1.29 & 9.4 \\
\hline
\end{tabular}

${ }^{*}$ Calculated relative to the $\mathrm{An}^{+}$ion.

${ }^{+}$Calculated relative to the detection efficiency of $\mathrm{An}^{+}$ion. 


\section{Z-MATRICEs FOR THE NEUTRAL ANILINE AND ITS CATIONS}

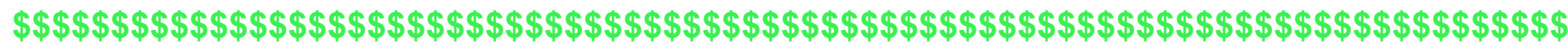

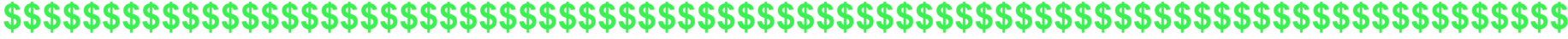

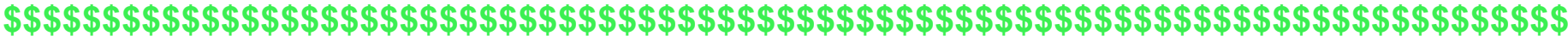

\section{ANILINE_NEUTRAL AND ITS CATIONS WITH THIS TOPOLOGY}

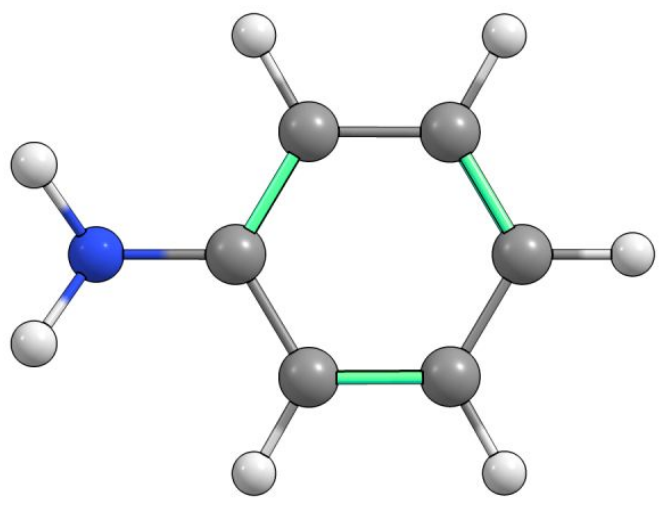

01

C

C 1 R12

C 1 R13

$\begin{array}{lll}\text { H } & 1 & \text { R14 }\end{array}$

2 A213

C 2 R25

2 A214

$1 \mathrm{~A} 125$

3 D3214

H 2 R26

1 A126

3 -D3125

$\begin{array}{lll}C & 3 & \text { R37 }\end{array}$

1 A137

3 D3126

H 3 R38

1 A138

$\begin{array}{ll}2 & -\mathrm{D} 2137\end{array}$

C 5 R59

2 A259

2 D2138

N 5 R5_10

9 A95_10

$1 \quad$ D1259

H 9 R9_11

5 A59_11

7 -D795_10

H 7 R7_12

9 A97_12

2 D259 11

H 10 R10_13

5 A5_10_13

H 10 R10_14

5 A5_10_14

5 -D597_12

Variables:

R12 =

$\mathrm{R} 13=1.40085560$

$\mathrm{A} 213=120.80442590$

$\mathrm{R} 14=1.09298292$

$\mathrm{A} 214=119.15337884$

$\mathrm{D} 3214=179.93793620$ 


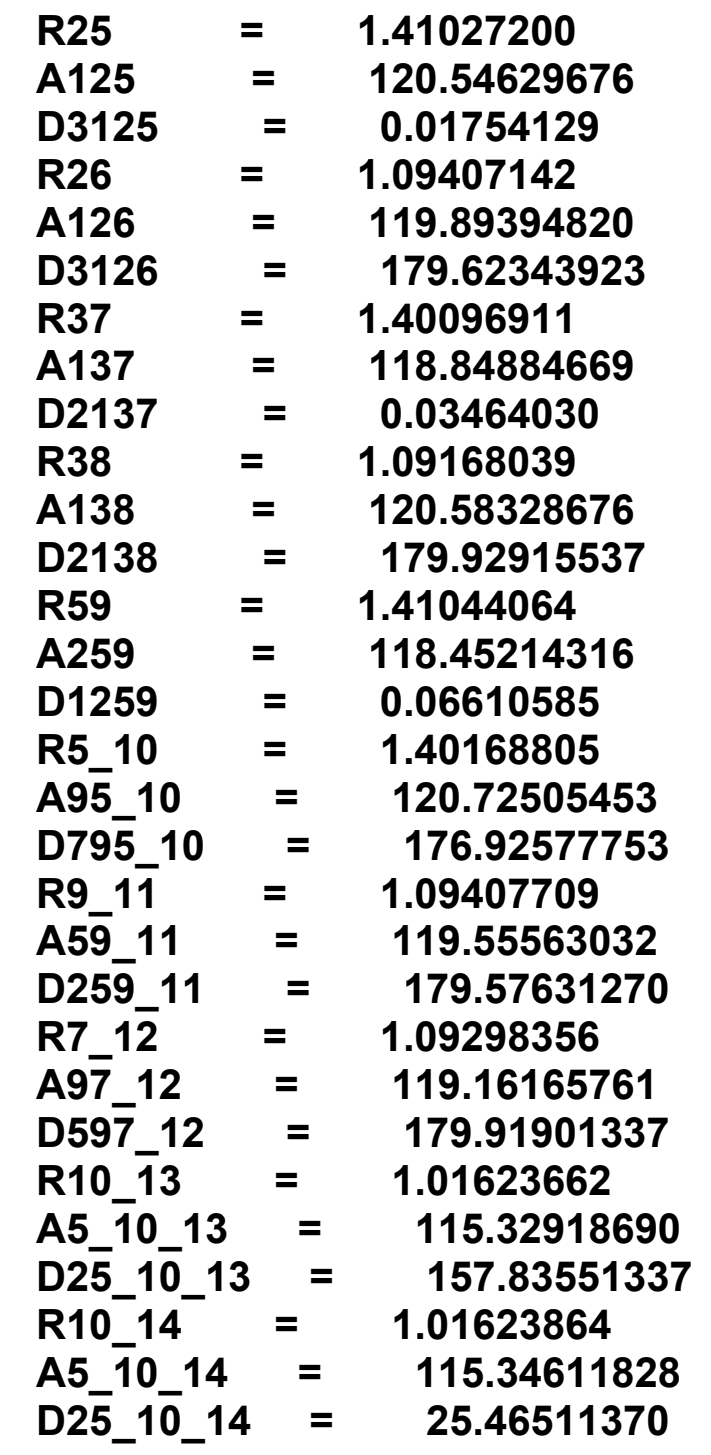

\footnotetext{
ANILINE_CATION

$+12$

C

C 1 R12

C 1 R13

H 1 R14

2 A213

C 2 R25

H 2 R26

3 A314

1 A125

2 D2314

1 A126 3 D3126

$\begin{array}{lll}C & 3 & \text { R37 }\end{array}$

1 A137

3 -D3126

H 3 R38

1 A138

$\begin{array}{ll}2 & \text { D2137 }\end{array}$

C 5 R59

2 A259

2 D2138

N 5 R5_10

H 9 R9_11

H 7 R7_12

9 A95_10

1 -D1259

H 10 R10_13

5 A59_11

7 -D795_10

3 A37_12

2 -D259_11

1 D137-12

H 10 R10_14

5 A5_10_13

2 D25_10_13

5 A5_10_14

2 D25_10_14

Variables:
} 


\begin{tabular}{|c|c|c|}
\hline $\begin{array}{l}\text { R12 } \\
\text { R13 }\end{array}$ & $\begin{array}{l}= \\
=\end{array}$ & $\begin{array}{l}1.37873590 \\
1.41806398\end{array}$ \\
\hline A213 & $=$ & 120.17765647 \\
\hline R14 & $=$ & 1.09070090 \\
\hline A314 & $=$ & 119.78935765 \\
\hline D2314 & $=$ & 179.99925648 \\
\hline R25 & $=$ & 1.43899580 \\
\hline A125 & $=$ & 119.35708360 \\
\hline D3125 & $=$ & 0.00301543 \\
\hline R26 & $=$ & 1.09209903 \\
\hline A126 & $=$ & 121.02419330 \\
\hline D3126 & $=$ & 179.99716016 \\
\hline R37 & $=$ & 1.41804639 \\
\hline A137 & $=$ & 120.80723267 \\
\hline D2137 & $=$ & 0.00161997 \\
\hline R38 & $=$ & 1.09131000 \\
\hline A138 & $=$ & 119.59449998 \\
\hline D2138 & $=$ & 179.99825963 \\
\hline R59 & $=$ & 1.43902904 \\
\hline A259 & $=$ & 120.12365502 \\
\hline D1259 & $=$ & 0.00588316 \\
\hline R5_10 & $=$ & 1.34333800 \\
\hline A95_10 & $=$ & 119.93598689 \\
\hline D795_10 & $=$ & 179.99933213 \\
\hline R9_11 & $=$ & 1.09210112 \\
\hline A59_11 & $=$ & 119.61391552 \\
\hline D259_11 & - & 179.99618654 \\
\hline R7_12 & $=$ & 1.09070001 \\
\hline A37_12 & $=$ & 119.79244856 \\
\hline D137_12 & $=$ & 179.99647671 \\
\hline R10_13 & $=$ & 1.01872191 \\
\hline A5_10_13 & $=$ & 121.74152178 \\
\hline D25_10_13 & $=$ & 0.00691648 \\
\hline R10_14 & $=$ & $\begin{array}{l}1.01871949 \\
12171306595\end{array}$ \\
\hline D25_10_14 & & 179.99955089 \\
\hline
\end{tabular}

\section{ANILINE DICATION}

$+21$

$\begin{array}{lllllll}\text { C } & & & & & & \\ \text { C } & 1 & \text { R12 } & & & & \\ \text { C } & 1 & \text { R13 } & \text { 2 } & \text { A213 } & & \\ \text { H } & 1 & \text { R14 } & \text { 3 } & \text { A314 } & 2 & \text {-D2314 } \\ \text { C } & 2 & \text { R25 } & \text { 1 } & \text { A125 } & \text { 3 } & \text { D3125 } \\ \text { H } & 2 & \text { R26 } & \text { 1 } & \text { A126 } & \text { 3 } & \text {-D } 3126 \\ \text { C } & 3 & \text { R37 } & \text { 1 } & \text { A137 } & \text { 2 } & \text {-D2137 } \\ \text { H } & 3 & \text { R38 } & \text { 1 } & \text { A138 } & \text { 2 } & \text { D2138 } \\ \text { C } & 5 & \text { R59 } & \text { 2 } & \text { A259 } & \text { 1 } & \text { D1259 }\end{array}$




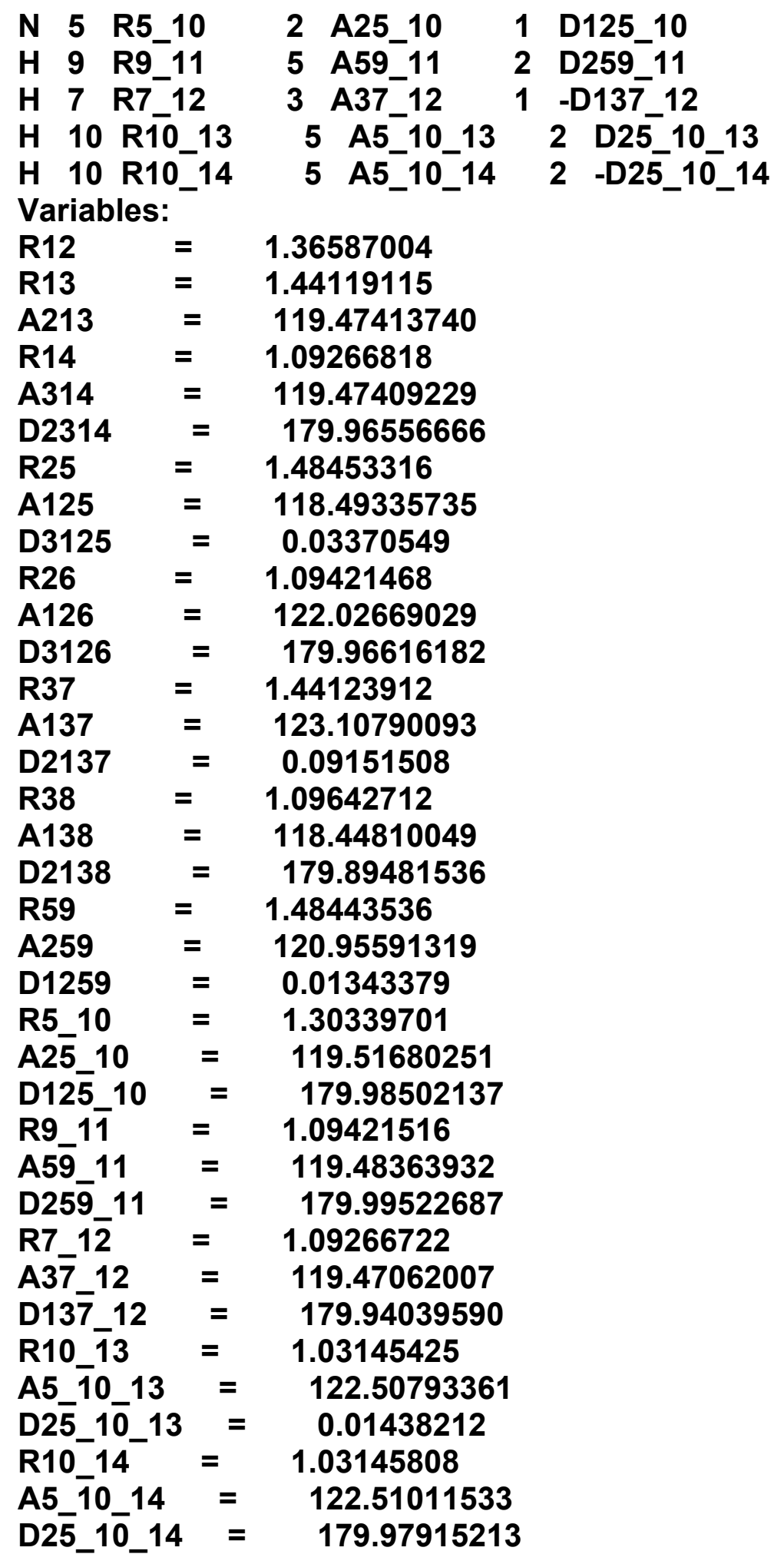

\footnotetext{
ANILINE TRICATION

$+32$

C

C 1 R12

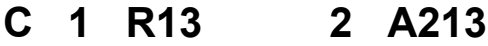




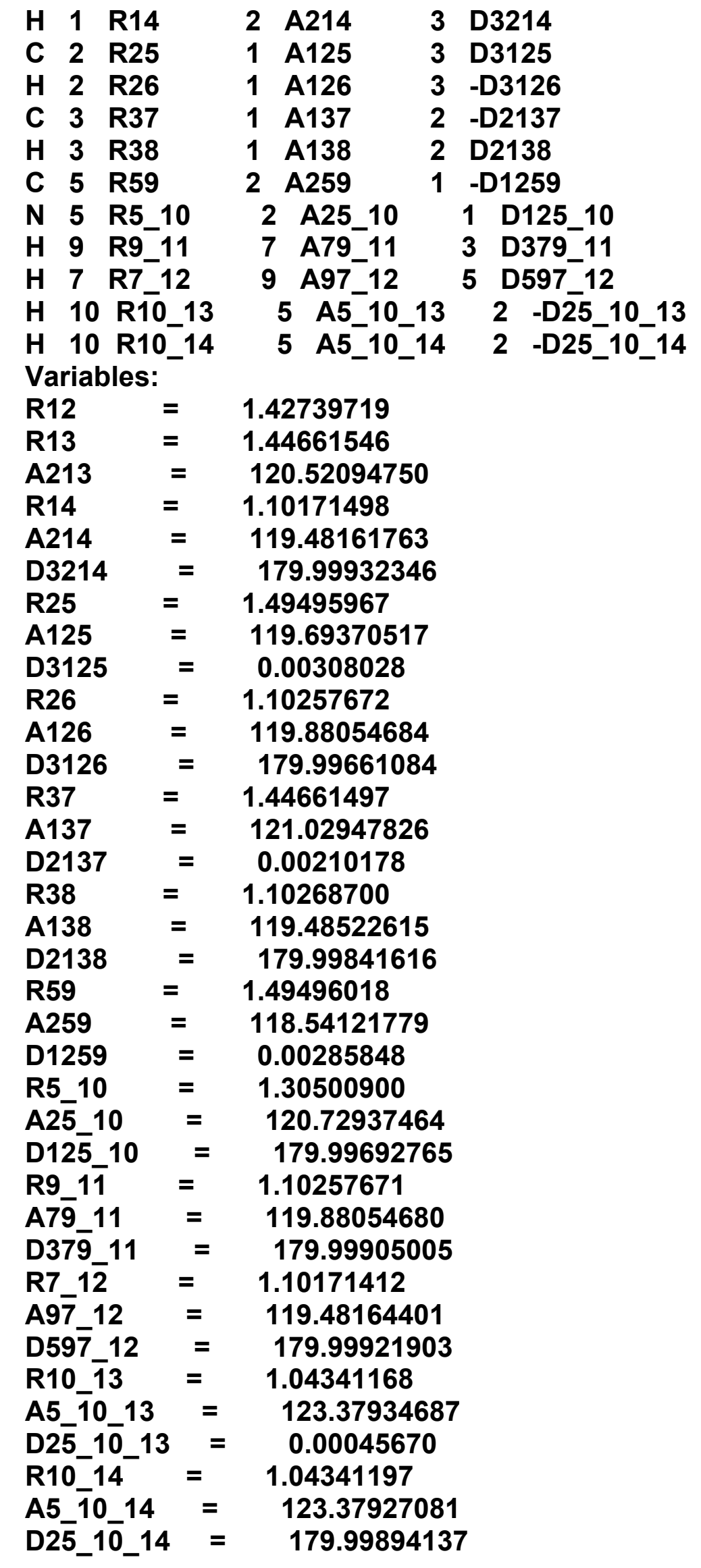




\section{DICATION GS}

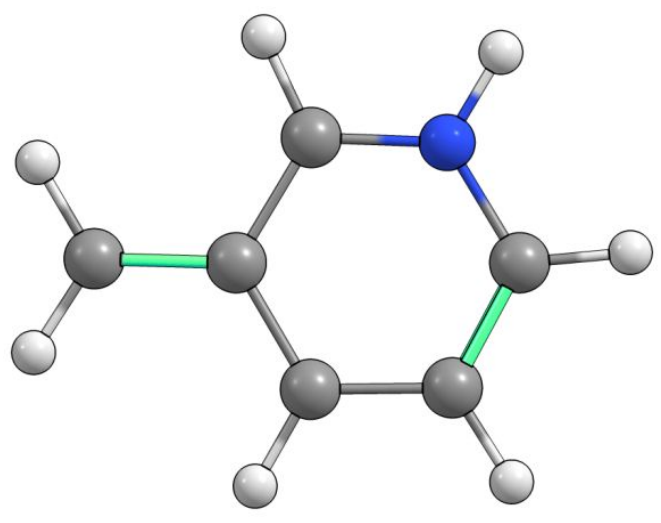

$+21$

C

N 1 R12

C 1 R13

H 1 R14

$2 \quad$ A213

C 2 R25

2 A214

1 A125

3 D3214

H 2 R26

$1 \mathrm{~A} 126$

3 D3125

C 3 R37

1 A137

3 D3126

$\begin{array}{lll}\text { H } & 3 & \text { R38 }\end{array}$

1 A138

2 D2137

C 7 R79

$3 \quad$ A379

2 D2138

C 9 R9_10

5 A59_10

1 D1379

H 10 R10_11

9 A9_10_11

2 D259_10

H 10 R10 12

H 7 R7_13

9 A9_10_12

7 D79 $10 \_11$

9 A97_13

7 D79 10_12

H 5 R5_14

2 A25_14

10 D10_97_13

Variables:

R12 =

$=\quad 1.37810652$

R13 =

$\mathrm{A} 213=120.47087979$

R14 = 1.09307393

$\mathrm{A} 214=115.92911233$

$\mathrm{D} 3214=180.00000000$

$\mathrm{R} 25=1.33611305$

$\mathrm{A} 125=123.26877105$

$\mathrm{D} 3125=\mathbf{0 . 0 0 0 0 0 0 8 5}$

R26 = 1.02971622

$\mathrm{A} 126=117.96177109$

$\mathrm{D} 3126=180.00000000$

R37 = 1.39566442

$\mathrm{A} 137=118.97860227$

$\mathrm{D} 2137=0.00000000$

R38 = 1.09196508 


\begin{tabular}{|c|c|c|}
\hline 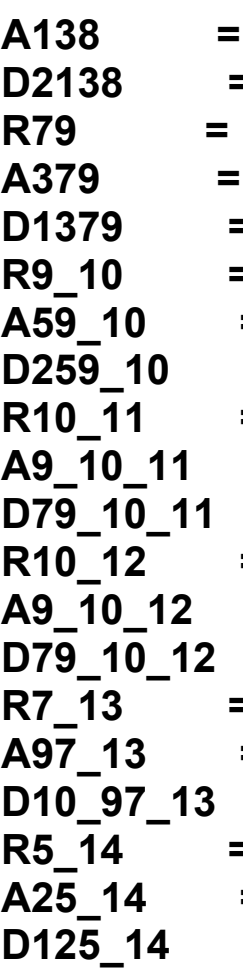 & $\begin{array}{l}= \\
= \\
= \\
= \\
= \\
= \\
= \\
= \\
= \\
= \\
= \\
= \\
= \\
= \\
=\end{array}$ & $\begin{array}{c}119.34099946 \\
180.00000000 \\
1.43993460 \\
119.79390067 \\
0.00000085 \\
1.39811628 \\
119.38623643 \\
180.00000000 \\
1.09613064 \\
121.25188266 \\
0.00000000 \\
1.09612517 \\
122.12037987 \\
180.00000000 \\
1.09401657 \\
119.83482303 \\
0.00000000 \\
1.09345748 \\
117.47175275 \\
179.99999915\end{array}$ \\
\hline
\end{tabular}

TRICATION GS:

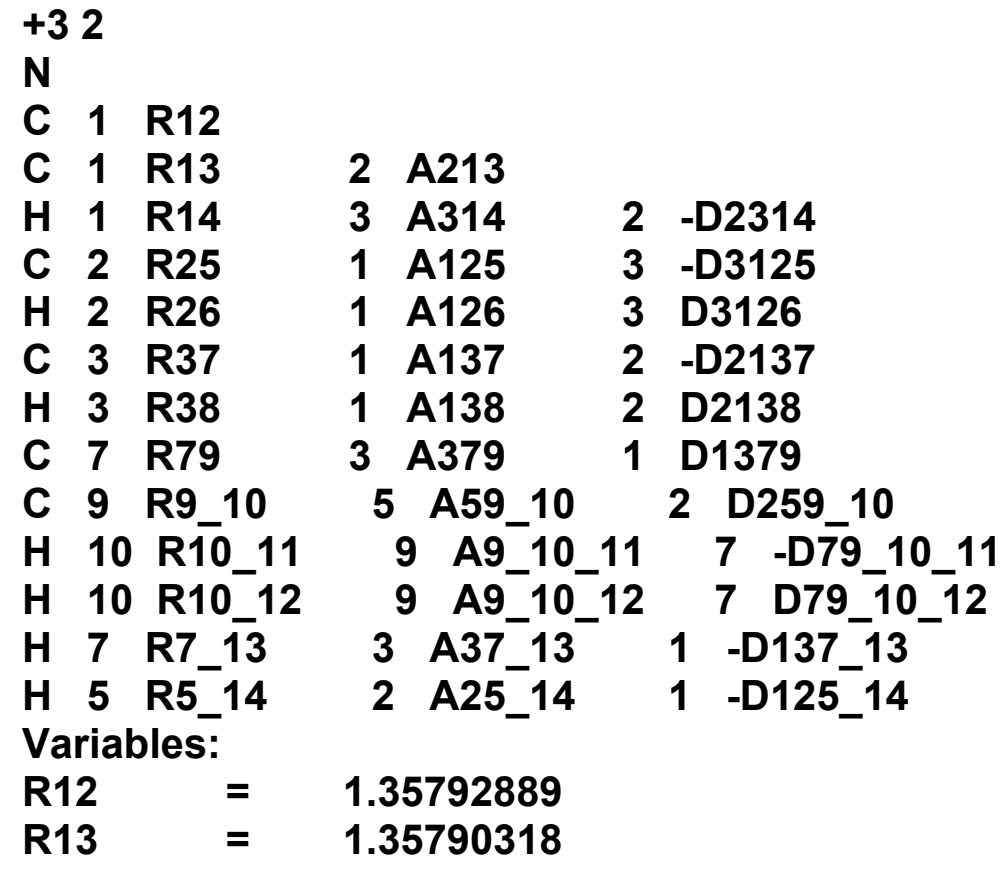




\begin{tabular}{|c|c|c|}
\hline A213 & $=$ & 123.28461928 \\
\hline R14 & $=$ & 1.04384201 \\
\hline A314 & $=$ & 118.35540691 \\
\hline D2314 & $=$ & 179.99959267 \\
\hline R25 & $=$ & 1.46657278 \\
\hline A125 & $=$ & 119.51172020 \\
\hline D3125 & $=$ & 0.01333924 \\
\hline R26 & $=$ & 1.10198041 \\
\hline A126 & $=$ & 118.15004487 \\
\hline D3126 & $=$ & 179.98301050 \\
\hline R37 & $=$ & 1.46652776 \\
\hline A137 & $=$ & 119.51467049 \\
\hline D2137 & $=$ & 0.01435620 \\
\hline R38 & $=$ & 1.10197968 \\
\hline A138 & $=$ & 118.14268006 \\
\hline D2138 & $=$ & 179.98224577 \\
\hline R79 & $=$ & 1.42947577 \\
\hline A379 & $=$ & 119.90201958 \\
\hline D1379 & $=$ & 0.02092135 \\
\hline R9_10 & $=$ & 1.45333000 \\
\hline A59__10 & $=$ & 121.05772869 \\
\hline D259⿱一𫝀口_10 & $=$ & 179.97531474 \\
\hline R10_11 & $=$ & 1.10396794 \\
\hline A9_10_11 & $=$ & 121.58380567 \\
\hline D79̄_10__11 & $=$ & 0.03043694 \\
\hline R10_12 & $=$ & 1.10396793 \\
\hline A9_10_12 & - & 121.58382447 \\
\hline D79_10_12 & - & 179.96614466 \\
\hline R7_13 & 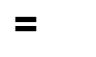 & 1.10090458 \\
\hline A37_13 & $=$ & 117.19643724 \\
\hline D137_13 & $=$ & 179.97430334 \\
\hline R5_14 & $=$ & 1.10090650 \\
\hline A25_14 & $=$ & 117.19354953 \\
\hline D125_14 & $=$ & 179.98454109 \\
\hline
\end{tabular}




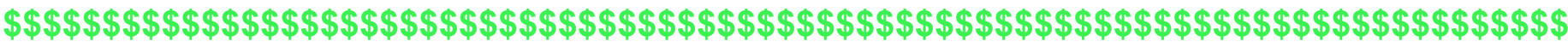

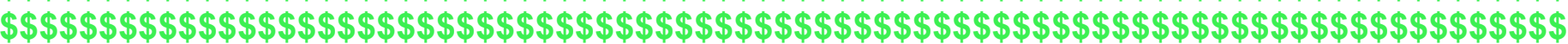

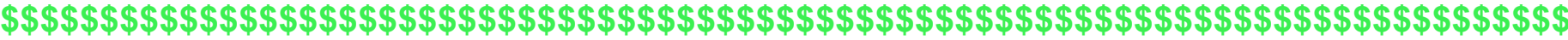

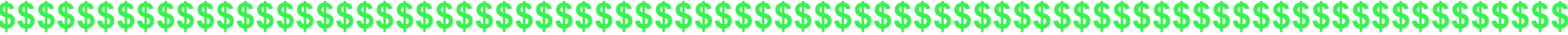

\section{Cartesian Coordinates and Imaginary Frequencies of all transition states presented in Figures 2-9}

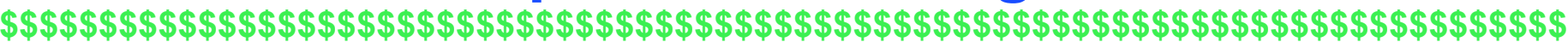

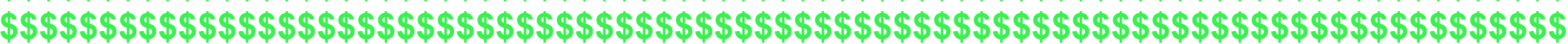

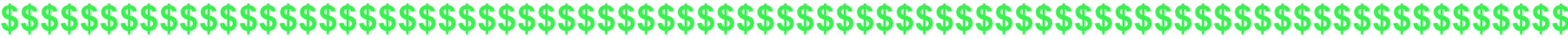

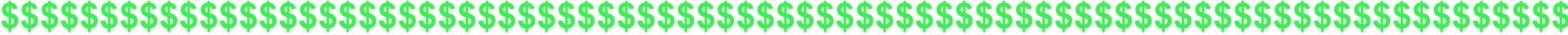

CAUTION: To be on a safer side, one should use triplet state guesses when dealing with singlet states (to make open-shell singlets)

We have used the following keyword parameters:

OPT $=$ (MaxCycle $=900$, Cartesian, calcfc,ts, noeigentest)

IRC(CalcFC,NoGradStop,MaxPoints=500,Recorrect=Never,ReCalc=5)

NEUTRAL PATHWAYS I in Figure 2:

TS1: anil_C_TS_49907_s.out

\# BPW91/6-311+G* scf=(VSHIFT=25,NolncFock,MAXCYC=77,Tight,NoVarAcc) N OSYMM IOP(5/13=1,5/36=1,8/11=1) INT=UltraFine OPT $=($ MaxCycle=900,Carte sian,calcfc,ts,noeigentest)

TITLE

C

C

C

C

C

C

N

H

H

H
0.076540341716

0.064197130365

$\mathbf{0 . 0 8 4 8 8 0 8 6 7 9 9 0}$

$-0.026874342579$

0.019213830737

0.042942378141

0.059629993553

0.109471140000

0.041958947529

$-0.006523510699$
$-1.159515450664$

0.226849938694

$-1.818984595624$

1.086495763478

0.323930763381

$-1.055610950121$

2.465113535646

$-1.738977187646$

0.748036144325

0.896353161557
1.194152472200

1.277464951733

$-0.043492620022$

$\mathbf{0 . 0 6 7 8 0 6 0 0 3 8 5 8}$

$-1.205646405207$

$-1.232655823604$

0.221495507494

2.120285572332

2.236238256887

$-2.136949519741$ 


$\begin{array}{rrrr}\text { H } & 0.050680030899 & -1.566480805290 & -2.199480886880 \\ \mathrm{H} & 0.104948557262 & -2.908734365797 & -0.089690760932 \\ \mathrm{H} & -1.170768260812 & 1.059369727241 & 0.281626341179 \\ \mathrm{H} & 0.000392895999 & 2.894464320791 & -0.713983089493\end{array}$

END

$\begin{array}{lll}1 & 2 & 3 \\ \text { A } & \text { A } & \text { A }\end{array}$

$\begin{array}{llll}\text { Frequencies }-- & -632.7330 & 158.8511 & 356.1846\end{array}$

TS2: anil_CC_TS_45357.out

\begin{tabular}{ll} 
TITLE & \multicolumn{1}{|c}{} \\
C & $-1.5713534959,-0.2470340791,0.0468081098$ \\
C & $-1.3244208135,0.909264401,-0.7173840017$ \\
C & $-0.6315657223,-1.2714008367,0.1235489633$ \\
C & $1.0015767791,0.890570588,0.4109434998$ \\
C & $1.4038791113,-0.179916389,-0.4159611198$ \\
C & $0.5153543069,-1.1737225037,-0.7681018333$ \\
N & $1.0941788912,1.755798356,1.2790544369$ \\
H & $-2.3484089462,-0.1958941329,0.8173149877$ \\
H & $-1.9686991295,1.7828299693,-0.5971798639$ \\
H & $2.3030681702,0.0409630983,-1.00419235$ \\
H & $0.5079780548,-1.5706256335,-1.7899077478$ \\
H & $-0.4909433276,-1.7377236716,1.1062291561$ \\
H & $-0.6699040124,0.9050764447,-1.5859471028$ \\
H & $1.7094328074,1.5660209436,2.0861758628$
\end{tabular}

END

$\begin{array}{lll}1 & 2 & 3 \\ \text { A } & \text { A } & \text { A }\end{array}$

$\begin{array}{llll}\text { Frequencies }-- & -444.4697 & 143.8547 & 201.4095\end{array}$

\section{NEUTRAL PATHWAY II in Figure 2:}

TS1: anil_ST_TS_51421.out

TITLE

C

法

C $\quad 0.6356278892,0.8982221033,0.1303478986$

C $\quad 0.5976110152,-1.4672494554,-0.0928296063$

C $\quad-0.8249436724,0.9522066976,-0.0230952817$

C $\quad-1.538508181,-0.2914171963,0.0704224737$

C $\quad-0.8224008562,-1.4741176086,0.085296132$

N $\quad 0.9570190553,2.0336782407,0.756460708$ 
H $\quad 2.4388185717,-0.3301023532,-0.217813128$

H $\quad-1.166490683,1.6325214157,-0.8184774432$

H $\quad-2.6317081628,-0.3052489144,0.0452275177$

H $\quad-1.3399916786,-2.4334079288,0.150447888$

H 1.1154821305,-2.4285916603,-0.1583138285

H $\quad 1.9047702155,2.4301221483,0.666409688$

H $\quad-0.4613556146,2.1229628001,0.7462545132$

END

$\begin{array}{lll}1 & 2 & 3 \\ \text { A } & \text { A } & \text { A }\end{array}$

Frequencies -- $-1880.4713 \quad 202.8246 \quad 347.8970$

TS2 anil_ST_TS_52039.out

\section{TITLE}

\begin{tabular}{|c|c|c|c|}
\hline C & -0.24011 & -0.73475 & 1.42622 \\
\hline C & -1.2825 & -0.38977 & 0.51812 \\
\hline C & 1.12356 & -0.75661 & $1.1765 t$ \\
\hline C & -1.20823 & 0.23417 & $-0.699 c$ \\
\hline C & 1.01299 & 0.62544 & -0.825 \\
\hline C & 1.64522 & -0.34315 & -0.076 \\
\hline $\mathbf{N}$ & -1.70497 & 0.757 & -1.7143 \\
\hline H & -0.58169 & -1.1942 & 2.358 \\
\hline H & -2.25843 & -0.85831 & 0.703 \\
\hline$H$ & 1.28464 & 0.82749 & -1.862 \\
\hline H & 2.49531 & -0.89441 & -0.497 \\
\hline H & 1.76467 & -1.2889 & 1.8840 \\
\hline H & -2.46123 & 1.43868 & -1.561 \\
\hline H & 0.5 & $1.4 t$ & \\
\hline
\end{tabular}

END

$\begin{array}{lll}1 & 2 & 3 \\ \text { A } & \text { A } & \text { A }\end{array}$

$\begin{array}{llll}\text { Frequencies }-- & -460.6479 & 141.1865 & 249.6377\end{array}$

CATION PATHWAY in Figure 3:

TS1: anil+_P2_TS_23563.out

TITLE
C
1.372571737012
$-0.308367561593$
$-0.165624911610$
C $\quad 0.650898947774$
0.910876729504
0.000226563249 


$\begin{array}{cc}\text { C } & 0.616041200164 \\ \text { C } & -0.823428410901 \\ \text { C } & -1.530730352230 \\ \text { C } & -0.798365233360 \\ \text { N } & 0.963516236434 \\ H & 2.463650322012 \\ H & -1.261799579258 \\ H & -2.622068495692 \\ \text { H } & -1.324732191780 \\ H & 1.129254179321 \\ H & 1.905686610078 \\ H & -0.527594969569 \\ \text { END } & \end{array}$

$\begin{array}{ll}1 & 2 \\ \text { A } & \text { A }\end{array}$

Frequencies -- -1768.3840
$-1.474889571977$

0.949755529396

$-0.261533845617$

$-1.461394265648$

2.078754371075

$-0.333814226713$

1.717177392830

$-0.276862163126$

$-2.412898345188$

$-2.438600558055$

2.313632999677

2.035403515488
$-0.095395201135$

$-0.073919761819$

0.074128197771

0.078833560426

0.537715119538

$-0.185580105724$

$-0.738229202325$

0.092889712225

0.169034444005

$-0.108080544517$

0.877862310479

0.730679819369
2

3

A

176.6442

307.9179

TS2: anil+_P2_TS_11363.out

TITLE

C $\quad 1.623172336561 \quad-0.205472849131$

$\begin{array}{lll}\text { C } & 0.515537360246 & 0.774562528304\end{array}$

$\begin{array}{lll}\text { C } & 1.369860174398 & -1.513193377368\end{array}$

$\begin{array}{lll}\text { C } & -\mathbf{0 . 7 9 0 2 0 6 3 3 4 7 1 0} & \mathbf{0 . 2 1 7 6 8 5 5 8 2 1 7 7}\end{array}$

C $\quad-1.077634038196 \quad-1.066925419473$

C $\quad \mathbf{0 . 0 4 0 3 4 0 3 2 5 5 4 6} \quad-1.939278230185$

$\begin{array}{lll}\mathrm{N} & -0.931036763391 & 2.871840810828\end{array}$

$\begin{array}{lll}\text { H } & 2.637896896025 & 0.143054347597\end{array}$

H $\quad 0.550137853921 \quad 1.351045470010$

H $\quad-\mathbf{2 . 0 8 8 6 0 8 4 9 1 0 5 3}-1.426231578018$

H $\quad-0.135385531310 \quad-2.984366121366$

$\begin{array}{lll}\text { H } & 2.184177795517 & -2.234834211803\end{array}$

$\begin{array}{lll}\text { H } & 0.665946162010 & 1.607581997998\end{array}$

$\begin{array}{lll}\text { H } & -1.609336745462 & 3.522986050452\end{array}$

END

1

Frequencies -- $\quad-\mathbf{8 8 . 3 2 4 0}$
$2 \quad 3$

A A

$33.0230 \quad 118.3857$

\section{DICATION PATHWAY in Figure 3:}

TS1: anil++_A49907_TS_73000.out

\section{TITLE}

C $\quad-0.1991103294,-1.0493944928,1.1601149142$

C $\quad 0.0869889231,0.3137435815,1.1495851974$

C $\quad-0.0619697143,-1.7498509866,-0.0957067408$

C $\quad 0.1408546266,1.0157510648,-0.165074233$

C $\quad 0.3559579279,0.2964245991,-1.4048142547$ 
C $\quad 0.2537310424,-1.0961711852,-1.3220428996$

N $\quad-0.4180611755,2.153010751,0.1372583887$

H $\quad-0.4441146824,-1.5917557374,2.0790811642$

H $\quad 0.6768292022,0.7753289061,1.9816007796$

H $\quad 0.5007571819,0.8127163973,-2.3602389533$

H $\quad 0.3367460935,-1.6968177101,-2.2327798991$

H $\quad-0.1794138259,-2.8393713737,-0.099508281$

H $\quad-0.7143501025,1.3280920907,1.496012135$

H $\quad-0.8841551673,2.7806040951,-0.5463173178$

END

$\begin{array}{lll}1 & 2 & 3 \\ \text { A } & \text { A } & \text { A }\end{array}$

Frequencies -- $-1447.3090 \quad 153.6798$
250.7788

TS2: anil++_P2i_TS_S_59873.out

\section{TITLE}

C

C

C

C

C

C

N

H

H

H

H

H

H

H

END
-1.650573881507
-1.101376799880
-0.809592211569
0.302618803869
1.250388535665
0.587002785092
2.637351567326
-2.744235226191
-1.554399967762
2.339260985945
1.261262268033
-1.224426531658
-1.459046571773
2.918946244659

$\begin{array}{ll}1 & 2 \\ \text { A } & \text { A }\end{array}$

Frequencies -- -87.7920
23

A A
$-0.733728066913$
0.165928685506
0.689185747930
0.126771303924
$-1.825673636778$
0.127771756749
0.556166575866
0.051899701620
$-0.349655525077$
$-1.662768621958$
3.328724036502
$-0.805063138747$
1.230590820556
$-0.247625267952$
$-2.530579786691$
$-2.838895934406$
1.242469970067
4.344802827734
$\mathbf{0 . 0 5 1 1 1 1 8 3 8 0 1 4}$
$-0.081840302471$
0.225419993416
$-0.738870256258$
$-0.052980831880$
0.020292648190
0.156939746665
1.028763781414
$-0.100106060359$

\section{IZOMERIZATION of ANILINE DICATION (Figure 4)}

TS1: anil++_Xi_TS_75240.out

TITLE
C
C
0.353465294866
0.014740465220
1.207349399228
1.041217846321
C
$-0.916277311399$
$-0.538078830109$

0.784354359312

0.493121952212

1.160176044902 
$\mathbf{C}$
$\mathbf{C}$
$\mathbf{C}$
$\mathbf{N}$
$\mathbf{H}$
$\mathbf{H}$
$\mathbf{H}$
$\mathbf{H}$
$\mathbf{H}$
$\mathbf{H}$
$\mathbf{H}$

END
$-1.409993322738$

$\mathbf{0 . 9 5 6 9 8 1 4 2 7 7 9 1}$

$-1.807521794674$

$-0.146938888462$

1.541150407688

1.582373588172

1.726223877163

$-2.868426858555$

$-1.150846084071$

0.062672247481

$-2.167451982510$
0.175504382475

0.067900542194

$-0.361921189059$

0.360771815885

0.052964659458

2.011592872007

$-0.598887265268$

$-0.582791811341$

$-0.970460796380$

0.594634039850

0.403663267504
$-1.154249645320$

$-0.632519944317$

0.129155931058

$-1.513598844028$

1.359085358888

0.845657813651

$-1.032326923215$

0.280291681241

2.136743528560

$-2.493686530878$

$-1.910444783384$ $\begin{array}{lll}1 & 2 & 3\end{array}$

A A A

Frequencies -- -708.2966
233.4540
315.7166

TS2: anil++_XC-Ri_TS_66721.out

\section{TITLE}

C

C

C

C

C

C

N

H

H

H

H

H

H

H

END

$\begin{array}{lll}1 & 2 & 3 \\ \text { A } & \text { A } & \text { A }\end{array}$

Frequencies -- -1193.1684
$-1.437493873015$ $-0.631312994057$

$-0.778360095293$

0.782682534559

1.462747191027

0.639224416642

$-0.048105629735$

$-2.530501551253$

$-1.024061978841$

2.506647044624

1.127979733850

$-1.354388568551$

$-0.093006316316$

1.221650086447
A
151.0914
$-0.190152513697$

0.974904515932

$-1.406781218835$

$\mathbf{0 . 8 0 6 1 3 0 2 3 0 7 6 8}$

$-0.313418351460$

$-1.498482423280$

2.026427175134

$-0.124556820290$

1.387641077969

$-0.336310485486$

$-2.464249048477$

$-2.309115397444$

2.927763297817

1.894199961336
0.000540432804

$-0.457691996773$

0.186559218190

$-0.317063039573$

0.086404124578

0.120101886702

$\mathbf{0 . 4 9 9 3 7 8 2 3 5 4 4 2}$

$-0.014674368633$

$-1.408204179979$

0.416046094772

0.296499470924

0.414086727327

$-0.035920160015$

0.213957553643

258.7680

TRICATION Pathway I The top panel in Figure 5: 
TS1: anil+++_negs_TS_2_97490.out

\section{TITLE}
C
C
0.297338203540
C
$-0.979993303390$
1.493591396323
$-0.947237982080$
C
0.319569044960
1.493647601623
$-1.587161914999$
0.366947578291
$-1.894538834846$
0.353676723691
2.370179508118
2.462981558460
$-2.369894134666$
$-0.294165445025$

$-1.791409599789$

0.094906428526

$-1.180882437888$

0.317515099345

$-1.010499741905$

0.280214153902

$-0.111947783202$

1.090196751706

0.437113424623

1.216673284933

$-2.891682581265$

$-1.759400416114$

1.800986209957

1.001171789991

$-1.535136744137$

1.461203381757

2.104422524227

0.223439213046

$\mathbf{0 . 3 4 2 8 8 3 0 8 0 7 7 7}$

$-0.188387194039$

$-0.359504991815$

0.094950550082

0.541643293939

1.218284228084

$-0.556649581880$

$-0.189629991944$

$-1.026311739765$

$-0.322910611154$

END

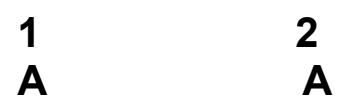

Frequencies -- -1736.4991
3

A

161.0907

210.6652

TS2: anil+++_negs_TS_2_89162.out

TITLE
$\mathbf{C}$
$\mathbf{C}$
$\mathbf{C}$
$\mathbf{C}$
$\mathbf{C}$
$\mathbf{C}$
$\mathbf{N}$
$\mathbf{H}$
$\mathbf{H}$
$\mathbf{H}$
$\mathbf{H}$
$\mathbf{H}$
$\mathbf{H}$
$\mathbf{H}$

END

$\begin{array}{lll}1 & 2 & 3\end{array}$

Frequencies -- -258.2551
1.241487667914

1.305375679307

0.010670932811

0.048793790557

$-1.305257449670$

$-1.230620372594$

0.171803846979

2.222424042303

2.272290255101

$-1.913298088481$

$-2.214919140359$

0.025441410798

0.232224589732

$-1.908667164399$
$-1.209962641814$

0.247114437882

$-1.917936720980$

0.667647097806

0.276227531081

$-1.238943752898$

3.302676860625

$-1.717730434632$

0.773923679127

0.459888500394

$-1.739618610093$

$-3.006708360787$

4.354518363802

0.748904050487
0.095436819683

$-0.143657864370$

0.214765831872

$-0.211524992486$

$-0.144215995349$

0.104582857663

$-0.651360074306$

0.176504915232

$-0.231269231055$

$-1.076447584080$

0.187465009282

0.394937637193

$-0.830639455904$

0.683532126627

\section{TRICATION Pathway II The bottom panel in Figure 5:}


TS1 anil+++_gs_TS_2_04877.out

\section{TITLE}

N

C

C

C

C

C

C

H

H

H

H

H

H

H

END
0.005075488389

1.248115823913

$-1.125502793181$

$-0.462498251690$

0.596018158454

$-1.186665327254$

1.507118224581

$-0.066411539122$

2.066931601133

$-0.882857204399$

$-1.870611076052$

$-2.082681452455$

2.485800933134

$-0.328932585452$
1.734680829051

1.312355393205

1.014309261836

$-1.646300170008$

$-0.962806884476$

$-0.373889971627$

$-0.035655143348$

2.722181855243

2.052057710570

$-2.551422809596$

$-0.571739239488$

1.527086873386

$-0.303770591577$

$-1.813647113173$
0.303555683062

$-0.131037418913$

0.239679375820

0.365199106578

$-0.256769986144$

$-0.201521768190$

$-0.563032740964$

0.631838901501

$-0.094222828968$

$-0.147279362450$

$-1.055806233493$

$\mathbf{0 . 4 7 8 2 6 0 4 2 7 4 6 4}$

$-1.032684025404$

1.463820870102

\section{3 \\ A $\quad A \quad A$ \\ Frequencies -- $-251.9148 \quad 142.9649 \quad 265.0522$}

TS2: anil+++_gs_TS_2_88558.out

No Z-Matrix found in chk file; cartesian coordinates used.

$\begin{array}{lrrr}\text { N } & -0.434151224443 & 2.582241775971 & 1.091434792844 \\ \mathrm{C} & 1.162008957704 & 0.505933672723 & -0.598315334818 \\ \mathrm{C} & -0.261909826660 & 0.753596998074 & -0.576798231703 \\ \mathrm{C} & -0.626536748155 & -1.587180420809 & 0.401958364250 \\ \mathrm{C} & \mathbf{0 . 7 5 6 9 2 7 0 8 7 8 6 5} & -1.441020113829 & 0.240555389369 \\ \mathrm{C} & -1.155928057596 & -0.237317329559 & -0.095701060797 \\ \mathrm{C} & 1.798803475174 & -0.744174811175 & -0.135084125642 \\ \mathrm{H} & -1.063289929236 & 3.423072674194 & 0.886770140024 \\ \mathrm{H} & 1.875727940687 & 1.250910174775 & -1.003634812069 \\ \mathrm{H} & -1.089508809562 & -2.421142012422 & -0.213015431389 \\ \mathrm{H} & -2.256372711412 & -0.134725238363 & -0.078687715342 \\ \mathrm{H} & -0.655693342305 & 1.576066992674 & -1.203586517131 \\ \mathrm{H} & 2.891501903095 & -0.932647272344 & -0.170974247827 \\ \mathrm{H} & -0.979968715157 & -1.803515089909 & 1.455068790232\end{array}$

Recover connectivity data from disk.

$\begin{array}{rrr}1 & 2 & 3 \\ \text { A } & \text { A } & \text { A }\end{array}$

$\begin{array}{llll}\text { Frequencies }- & -201.8193 & 78.2327 & 94.9577\end{array}$ 


\section{IZOMERIZATION OF BENZENE DICATION (Figure 6)}

\section{TOP PANEL}

TS1: c6h6++_TSb_s_31388.out

\section{TITLE}

C

C

C

C

C

C

$\mathrm{H}$

H

H

H

H

H

END
$-1.327987017288$

$-1.479455475816$

$-0.108534648280$

$-0.198029490870$

1.094727925572

1.117985523405

$-2.271681322573$

$-2.415163082770$

1.944657635313

2.101837723938

$-0.147673460872$

0.653165690241
$-0.524984769744$

0.917470967351

$-1.238892517934$

1.297170875242

0.874223976317

$-0.595145883526$

$-1.038650544377$

1.438166075219

1.478612454154

$-1.077261358277$

$-2.335331600322$

1.436522325895
$-0.012470103786$

0.012208497702

0.109800685389

0.079687985148

0.254985961978

0.146382371313

$-0.273169720157$

$-0.225675859751$

0.615752827828

0.212216597553

0.160254398373

$-0.943593641589$

\section{3}

A

A

Frequencies -- -1215.4848
A

287.3052
333.0672
TS2: c6h6++_TS_s_33114.out

\section{TITLE}

C

C

C

C

C

C

$\mathrm{H}$

H

H

H

H

H
$-1.649986354226$

$-0.710779177614$

$-1.035848170115$

0.692024759442

0.830271604088

0.468165775741

$-2.721494567628$

$-0.904213584270$

$\mathbf{1 . 2 0 7 2 4 1 4 1 8 1 8 4}$

1.121717230328

$-1.524141713327$

1.553672779398
$-0.215910795822$

$-0.036243813447$

$\mathbf{0 . 0 4 2 1 6 8 2 5 2 7 8 7}$

0.110281706922

1.328442034395

0.164304827710

$-0.393863385166$

0.107914411905

2.366656066681

$-0.140653077514$

0.258065872259

$-0.244132100709$
$-0.228402324276$

$-1.241831161987$

0.995210140742

$-0.686709100316$

0.077907496403

0.852961118659

$-0.377815739485$

$-2.313305421992$

0.095785130181

1.690133260179

1.955137756724

$-1.280711154831$ 
END

123

A A $A$

$\begin{array}{llll}\text { Frequencies -- } & -420.8681 & 340.8744 & 353.5374\end{array}$

BOTTOM PANEL

TS1: c6h6++_TSa_s_29358.out

TITLE
C
0.049363109279
$-0.095371342388$
$-1.289158421982$
C
$\mathbf{0 . 8 6 4 6 4 8 6 1 8 0 5 0}$
1.235609762380
0.215953199739
$-1.305246718904$
$-0.093640568532$
$-0.865964973753$
C
1.022173289108
$-0.019671375735$
$-0.197403590170$
$-0.130508595354$
0.399230428556
1.122160695610
$-1.447184263399$
0.267064510195
0.470335364864
$\mathrm{H}$
0.419471182696
$-0.050903579201$
$-2.324373475189$
1.008628530373
2.313907110068
0.068902224846
0.084153886777
0.560822458469
2.196120733451
$-2.396029576459$
0.390524230609
$-2.131643016765$
$-0.327174973340$
1.003811552468
0.405243554598
$-0.685906661082$
$-1.546260598163$
1.023057288277

END

\begin{tabular}{|c|c|c|c|}
\hline 1 & 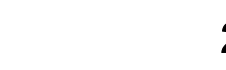 & 3 & \\
\hline A & & A & \\
\hline Frequencies -- & -676.0771 & 212.4825 & 387.1540 \\
\hline
\end{tabular}

TS2: c6h6++_TSa_S_33742.out

TITLE

C
C
C
C
C
C
H
H
H
H
H
H

0.880394337893

$-0.154264779237$

0.744489612705

0.718598338294

$-0.849554231162$

$-0.465432143233$

$-0.478484111205$

0.151955291717

$-0.220588724561$

1.221265889679

1.361065042992

$-0.519959277667$

$-0.460456963035$

0.559048677292

$-1.174823362126$

0.547481625918

$-1.116545089590$

1.798673934183

0.044385394970

$-0.404775652422$

1.432177202032

$-1.571128558166$

1.308690911851

$-0.888730297310$

$-0.904728609764$

$-0.882563346445$

$-2.231211947060$

$\mathbf{0 . 8 3 8 5 4 4 4 5 0 1 3 5}$

$-1.260035907404$

$-0.506358852926$

$-2.049147476077$

0.402999814933

2.123399341869

$-0.446549521883$

1.770909182651

0.465429802160

END

$\begin{array}{lll}1 & 2 & 3 \\ \text { A } & \text { A } & \text { A }\end{array}$




\section{IZOMERIZATION of ANILINE TRICATION (Figure 9)}

\section{TOP PANEL}

TS1:anil+++_dim_TS_2_00861.out

\section{TITLE}

N

C

C

C

C

C

C

H

H

H

H

H

H

H

END

\section{1}

A

Frequencies -- -915.3004
$-1.619000913608$

$-1.884197344190$

$-0.387007630438$

1.464628699868

0.562773811707

0.760094587004

$-0.840122651878$

$-2.438034135299$

$-2.938123180122$

$-0.343176740575$

1.237630881638

2.048788708028

1.761998044517

$-1.038042136410$
$-1.029640335310$

0.301906283743

$-1.619776310942$

1.566984598942

0.651555605109

$-0.833597114781$

1.212331086586

$-1.664637608172$

0.620918440981

$-2.717640091179$

1.429256999691

2.465045276151

$-1.279980056118$

2.283043225838
0.119854114372

0.002763023193

0.034492210403

0.351416304573

$-0.155124588286$

$-0.120187671161$

$-0.236017401173$

0.237410419592

0.000838570071

0.086695247133

$-1.015331106217$

0.661591269363

$-0.198129684044$

$-0.388230708070$
3

A

A

108.3938

252.9308

TS2: anil+++_dim_TS_2_01011.out

\section{TITLE}

N

C

C

C

C

C

C

H

H

H

H

H
$-1.485082893170$

$-1.672216411719$

$-0.325624207944$

1.128597445713

0.761070279790

0.867877970480

$-0.590397882696$

$-2.324922140697$

$-2.706888798138$

$-0.355465412696$

1.440966101612

1.349544099191
$-0.860428040296$

0.485819537762

$-1.549292024011$

1.591834522281

0.632832195533

$-0.847113738188$

1.309042694169

$-1.425597978748$

0.860146318642

$-2.645064894063$

1.071199233445

2.598163067022
0.211859959637

0.055501558462

$-0.018889658379$

0.584736679793

$-0.389591506802$

$-0.298166280992$

$-0.349851825331$

0.463222934868

0.105805263000

0.083979031407

$-1.235813074131$

1.014045817818 
H

END
1.835912297201

$-0.775160446968$
$-1.360428746167$

2.324657852401
$-0.412823411067$

$-0.731975488702$ $\begin{array}{lll}1 & 2 & 3 \\ \text { A } & \text { A } & \text { A }\end{array}$

Frequencies -- -411.3345
197.5121

298.9320

TS3: anil+++_dim_TS_2_93270.out

\section{TITLE}

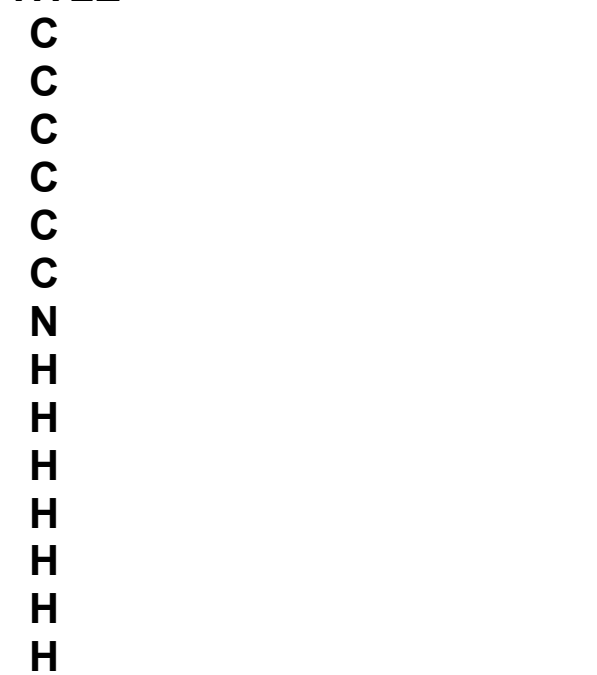

END

$\begin{array}{rr}-1.486985559502 & -0.180459665421 \\ -0.687460317538 & 0.957589007158 \\ -0.785042412677 & -1.394747673191 \\ 0.734600061787 & 0.868458175679 \\ 1.481022521361 & -0.295312966761 \\ 0.640955235955 & -1.469388598965 \\ 0.030035139487 & 1.933072972775 \\ -2.589329811544 & -0.126140224461 \\ -1.005896433243 & 1.404146451111 \\ 2.553614535871 & -0.291595030553 \\ 1.128663314510 & -2.420344925929 \\ -1.373745108456 & -2.291970339311 \\ 0.032611499252 & 2.602423236420 \\ 1.170657334875 & 2.078269581452\end{array}$

$-1.486985559502$

$-0.785042412677$

0.734600061787

1.481022521361

0.040955235955

0.030035139487

$-2.589329811544$

$-1.005896433243$

2.553614535871

1.128663314510

$-1.373745108456$

1.170657334875

$-0.180459665421$

0.957589007158

$-1.394747673191$

$-0.295312966761$

$-1.469388598965$

$-0.126140224461$

1.404146451111

291595030553
$-0.687460317538$

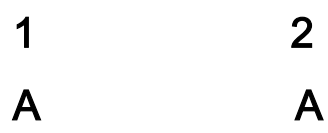

Frequencies -- -1619.0561
23

A

112.4650

\section{END}

A

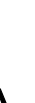

$-0.130389641806$

$-0.680813717647$

0.199491083707

$-0.251721013337$

0.169778802160

0.263195144300

0.272162515011

$-0.098775175652$

$-1.645612493051$

0.433805390115

0.542510474716

0.449729572349

1.097738560071

$-0.621079501402$ 


$\begin{array}{rrrr}\mathrm{C} & \mathbf{0 . 0 1 8 5 7 4 6 8 4 5 4 4} & 2.092587910726 & 0.134745544715 \\ \mathrm{H} & -2.556589680392 & -0.306981983505 & -0.109932758753 \\ \mathrm{H} & -1.096906505689 & 1.272495735316 & -1.497674145861 \\ \mathrm{H} & 2.559713862008 & -0.401220591316 & 0.196760346077 \\ \mathrm{H} & 1.045771911937 & -2.468484109827 & 0.421315273778 \\ \mathrm{H} & -1.288897457324 & -2.214265240594 & 0.469024508254 \\ \mathrm{H} & -0.011971943830 & 3.203533799103 & 0.254989821539 \\ \mathrm{H} & 1.209122557214 & 1.812062935962 & 0.497892381563\end{array}$

$\begin{array}{crrr}1 & 2 & 3 & \\ \text { A } & \text { A } & \text { A } & \\ \text { Frequencies -- } & -738.2087 & 177.4582 & 224.0541\end{array}$

TS2: anil+++_dim_TS_2_93270.out

\section{TITLE}

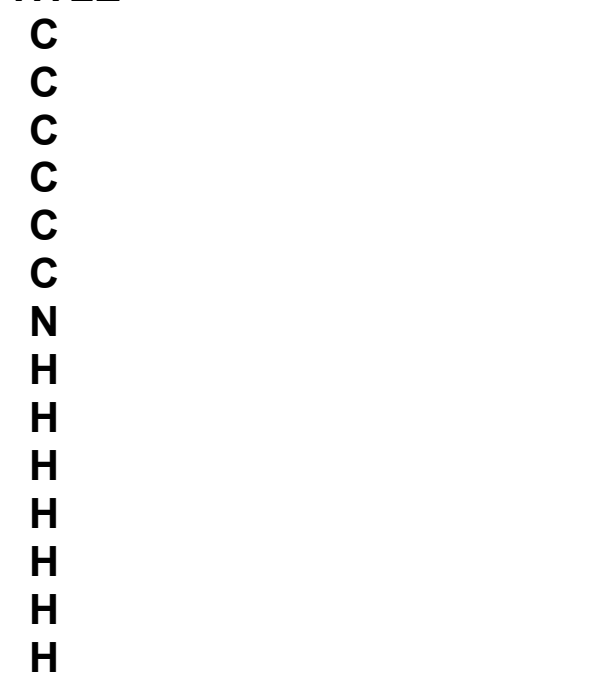

END
$-1.486985559502$
$-0.687460317538$
$-0.785042412677$
0.734600061787
1.481022521361
0.640955235955
0.030035139487
$-2.589329811544$
$-1.005896433243$
2.553614535871
1.128663314510
$-1.373745108456$
0.032611499252
1.170657334875

$-0.180459665421$

0.957589007158

$-1.394747673191$

$\mathbf{0 . 8 6 8 4 5 8 1 7 5 6 7 9}$

$-0.295312966761$

$-1.469388598965$

1.933072972775

$-0.126140224461$

1.404146451111

$-0.291595030553$

$-2.420344925929$

$-2.291970339311$

2.602423236420

2.078269581452
$-0.130389641806$

$-0.680813717647$

0.199491083707

$-0.251721013337$

0.169778802160

0.263195144300

0.272162515011

$-0.098775175652$

$-1.645612493051$

0.433805390115

0.542510474716

0.449729572349

1.097738560071

$-0.621079501402$

$1 \quad 3$
A
A

112.4650
203.5577

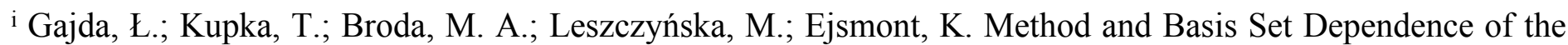
NICS Indexes of Aromaticity for Benzene. Magn. Reson. Chem. 2018, 56, 265-275.
} 